\title{
EXPLORING CREATIVITY THROUGH ARTISTS’ REFLECTIONS
}

\author{
Ryan DANIEL (D) * \\ James Cook University, College of Arts, Society and Education 4811, Townsville, Australia
}

Received 16 September 2019; accepted 11 October 2020

\begin{abstract}
The concept of creativity has been theorized and debated for millennia, dating back to the Greek philosopher Plato, who referred to "divine madness" in poets. Debates continue as to whether creativity is a gift or talent, a product of the genius gene, a side effect of mental health conditions, or if it is learned and nurtured through the environments and societies in which an individual grows and develops. While there is a wealth of research that sets out to define the concept of creativity, and numerous theoretical models have emerged since the early part of the 20th century, little of that involves artists reflecting on the concept. In order to explore this area, this study surveyed 314 artists from a range of countries, using an online survey, which invited them to reflect on creativity as a concept and how they understand it within their artistic practice. The findings reveal that creativity is a complex term and there is a range of understandings demonstrated by those who practice art-making. Questions for key stakeholders in education and policy are also raised, in terms of the role and place of artistic creativity in society.
\end{abstract}

Keywords: artistic practice, artists, creativity, genius, reflection, talent.

\section{Introduction}

Creativity pervades society and a range of areas of practice, be this in the arts, sciences, medicine, engineering, technology or business. The origins of the word can be found in the Latin "creare" (to make), the Sanskrit "kri" (to do), the Indo-European "kere" (to grow) and the Greek "krainein" (to fulfil), these origins reflecting both a process and accomplishment or reward. Artists have been closely associated with the realization of human creativity for millennia (Bryant \& Throsby, 2006; Chan et al., 2015; Wiggins et al., 2014). In early times, the ancient Greeks believed that creativity in poets, in particular, involved a divine spirit or spirits called daemons (Freeland, 2002; Kaufman, 2009), or that it required the intervention of a "muse" (Lubart, 2018). The philosopher Plato, who described the presence of "divine madness" in poets (Schlesinger, 2009, p. 62), noted that the term madness was not seen as derogatory, but rather a gift from the gods that poets would embrace in times of heightened sensitivities during which they were possessed (Sloan Allen, 2002; Dorter, 1973). While

\footnotetext{
*Corresponding author. E-mail: ryan.daniel@jcu.edu.au
} 
cautiously positive in relation to the value of art, Plato was also very distrustful of artistic skills and artists, frequently commentating that the imitation of life through art could easily lead to a distortion of reality and people being led astray (Sloan Allen, 2002). Artists have a long history of attracting attention in relation to creativity, for example they have even been regarded as alchemists who turned random items into works of aesthetic beauty (Friend, 2005). While these myths and perceptions have to a large extent faded, the concept of creativity through art-making remains an ongoing and complex area of theorization, debate and research (Lubart, 2018).

Perceptions remain today in relation to whether artists are afflicted by the "genius" gene (Bryant \& Throsby, 2006), whether they need to reach altered states of being through the intake of mind-altering substances (Bain, 2005), or whether their creativity is influenced by psychopathologic conditions such as bipolar disorder, manic depression, schizophrenia or Asperger syndrome (Cropley et al., 2010; Ghadirian et al., 2001; Runco, 2007; Weisberg, 1994). The literature also notes that artists are often extremely self-critical of their work, to the extent that it can become detrimental to their wellbeing (Kozbelt, 2016). Friend (2005, p. 160) argues that an artist's "urge to communicate their perceptions of the visible world (whether seen by outer or inner eye) is overwhelming: almost violent, almost a disease, a madness". Ceci and Kumar (2016, p. 610) agree to some extent and argue that "many artists are most prolific when they are least emotionally stable". In addition to these myths and perceptions, history profiles a tendency for depression leading to suicide in highly creative individuals, with artists such as Ernest Hemingway, Vincent van Gogh, Jimi Hendrix and Virginia Woolf (Runco, 2007), and more recently Kurt Cobain, Robin Williams, Avicii and Amy Winehouse taking this path. While suicide affects people from all sections of society, artists who choose this path tend to attract more attention, thereby creating a level of notoriety and even stigma that continues in today's society.

Prior to the middle of the 20th century, the concept of creativity had received marginal attention within the field of psychology (Kaufman, 2009). In 1926 however, the work of Graham Wallas was noted as influential when he argued that creativity involved a four-stage process: preparation, incubation, illumination and verification (Botella et al., 2013). This idea of creativity involving a staged process became established in the discourse and ongoing research in the field. In 1950 a new focus on creativity began after a meeting of the American Psychological Association and the presidential address by Joy Paul Guilford (Kaufman, 2009), who advocated strongly for the need to take the creativity concept far more seriously. Since that time, there has been an emerging consensus that creativity requires the elements of both novelty and appropriateness, in that there should be originality (a degree of uniqueness) and it should offer value or applicability in some form (Kaufman, 2009). This duality of novelty and appropriateness continues to underpin many contemporary understandings of the concept of creativity.

More recently, it has been argued that creativity requires a third aspect, namely high quality, although one of the problems with this for example, is that it does not cater to children, who are highly creative in their own way but whose work would not often be described as having significant aesthetic or social value (Kaufman, 2009). Similarly, many adults engage 
in creativity on a daily basis (e.g. cooking, planning, divergent thinking) however the outcomes are not necessarily meant to be evaluated as being of high quality per se. In addition to the individual aspects required for creativity to occur, it is also acknowledged that there is a sociocultural dimension, in that creativity needs to be recognized by both the domain or discipline (e.g. visual arts, photography) and by the field (e.g. audiences, key stakeholders), the latter of whom determine and identify the elements of originality, appropriateness and quality (Kaufman, 2009). There are tragic historical examples in relation to this idea of recognition, for example, van Gogh's paintings were not valued by the field during his lifetime, he lived in poverty and in a state of severe depression. Today however, his works are some of the most expensive and lauded in the field of painting.

While creativity is significant in all fields of human endeavor, it is most commonly communicated by artists who transport an audience beyond ordinary experience (Dorter, 1973). They prompt audiences to imagine, to reflect, to ponder and to challenge pre-existing thought patterns and social systems (Sternberg, 2018). Art can be powerful, it can stir up emotions in the viewer or the listener (Freeland, 2002). Lumsden (1999, p. 153) describes creativity as a "kind of capacity to think up something new that people find significant" while Boden (2005) refers to it as involving the exploration of conceptual spaces in people's minds. Friend (2005, p. 172) adds a somewhat ethereal element, arguing that "the artist should perform magic for us, the magic of transforming materials into something rich and strange, yet comforting". Sternberg (2018, p. 50) contends that

"creative work is not merely about challenge; it is about effective challenge-challenge that cannot only question things, but also that can question [an audience] effectively and potentially can change them".

Artists therefore play a key role in providing a window on society, their works often reflecting or commentating on key political, social, environmental and technological issues of the time.

While most definitions of the term creativity refer to new products, solutions to problems through the use of inventive means, imagination and routine skill (Bryant \& Throsby, 2006), ultimately there is no fixed definition or explanation of what creativity actually entails. As a consequence, Bryant and Throsby (2006, p. 510) argue that "the prospects for finding a clearcut definition of creativity are dim", Blair and Mumford (2007, p. 197) contend "there is still a lack of consensus as to a perfect definition" while Runco (2007) claims that the creative process is multifaced, and worse yet for those trying to define it, it is extremely complex. Wiggins et al. (2014) agree, arguing that while creativity is a "fundamental force in the development of humankind [...]. The concept of creativity itself is shrouded in imprecision and subjectivity". Hence, there is an ongoing argument for "more research, more data, and more synthesis of this future research" (Cropley et al., 2010, p. 13). Creativity therefore remains an area of interest in a range of fields and one that is very worthy of ongoing research and inquiry as applied to artists, a group whose views have received relatively limited recent attention in the literature. This study therefore set out to explore current artists' reflections on creativity as it applies to them and their practice. 


\section{Theories of creativity}

As indicated in the introduction, there is a wealth of literature that considers the origins of and key influences on creativity (Kozbelt et al., 2010). Many studies have focused on distinguishing between creativity as a trait and a process (Bryant \& Throsby, 2006). Even the notion of whether creativity is a valid concept has been debated; as far back as 1927 the statistician Charles Spearman claimed that no such special creative power exists (Runco, 2007). Other debates continue, including whether creativity is more likely to manifest itself in more intelligent individuals (Runco, 2007), and whether family background has the potential to "influence creative development both positively and negatively" (Bryant \& Throsby, 2006, p. 511). Eleven years after Guilford's 1950 address called for a far greater focus on creativity research in the field of psychology, James Melvin Rhodes produced a revised version of Wallas's 1926 four-stage concept of creativity. Rhodes 1961 publication established the "four Ps": person, process, product and press (environmental influences) (Botella et al., 2013; Maley \& Kiss, 2018; Sawyer, 2012). This theoretical model continues to be referred to in the research literature (Glăveanu, 2013).

Kozbelt et al. (2010, p. 20) state that moderation is needed when debating the concept of creativity, "where no one theoretical perspective is emphasized at the expense of others". In surveying the considerable body of extant literature, they determine that there are ten categories of creativity theory:

- Developmental (creativity develops over time);

- Psychometric (creativity can be measured with reliability and validity);

- Economic (creativity is influenced by market forces);

- Stage and componential process (creativity proceeds through stages and components);

- Cognitive (ideational thought processes are foundational);

- Problem solving and expertise-based (creative solutions result from a rational process that relies on domain expertise);

- Problem finding (creative people identify problems to be solved);

- Evolutionary (Darwinian) (eminent creativity results from blind generation and selective retention);

- Typological (creators have individual differences which can be classified) and

- Systems (creativity results from a complex system of interacting and interrelated factors).

While a detailed interrogation of these categories of creativity theory falls outside the scope and intent of this paper, they provide a useful basis for understanding the different ways in which creativity is explained. In addition, Kozbelt et al. (2010) highlight the fact that new theories of creativity will continue to emerge and, despite the wealth of extant literature, they argue it is an area of study that is still in its early phases.

Supporting the assertion by Kozbelt et al. (2010), further theories explaining concepts of creativity continue to emerge. Since the turn of the 21st century, the "four P's" definition of creativity has been extended to "six P's", adding persuasion (changing the way people think) and potential (unfulfilled possibilities and processes) (Kozbelt et al., 2010). Glăveanu (2013) proposes the "five A's" model, where person becomes actor, process becomes action, product becomes artefact and press becomes audience and affordances. This new holistic framework, 
Glăveanu (2013, p. 78) argues, does not offer definitive answers but it poses new questions about creativity that require ongoing interrogation and research inquiry, for example, "How do actors interact with audience members and become themselves 'audiences' for their own productions?".

Csikszentmihalyi (2014, pp. 227-238) focus less on what creativity is and more on where it is, arguing that social and environmental history and context are as important as any individual's creative traits or abilities. The authors argue that creativity involves three interacting forces: the field - social institutions that select variations worth preserving, the domain disciplines that preserve or transmit ideas to the next generation, and the individual - the person who brings about change. They cite two periods in history as key examples of when these interacting forces were at play. One was Florentine society of the 14th and 15th centuries, a period referred to as the Italian Renaissance, and the second was the city of Paris, France at the turn of the 20th century. In Paris, at that time, artists were lured there by a culture which promoted personal and artistic freedom, the latter leading to the emergence of such movements as impressionism, symbolism and cubism. In addition to their argument that three interacting forces are required to support creativity, Csikszentmihalyi (2014, pp. 227-238) touch on the concept of the genius, which they define as not just the traits of an individual but also a process of recognition and promotion by peers within a social field and cultural domain. They refer to Leonardo da Vinci as a key example, noting he was an artist and innovator who frequently moved to new Italian cities to pursue opportunities, be supported and funded to produce new work, and to engage with the key gatekeepers within the social field in order to have this new work recognized and acknowledged. This movement and recognition was, in their view, as important to his legacy as his innate ability.

Recently, Sternberg (2018) has developed a triangular theory of creativity that involves three facets: defying the crowd, defying oneself and defying the Zeitgeist. Defying the crowd refers to challenging existing ideas, and while this may be at odds with an artist's desire to be appreciated for their work, creative people are arguably aware that it is controversial ideas that have the potential to influence the field. Defying oneself refers to challenging one's own beliefs, practices and values, in order to avoid becoming entrenched in a set mode of thinking or working. In order to defy the Zeitgeist, Sternberg (2018) argues that one must unearth and challenge one's own presuppositions and that this may also be unconscious; the artist must question the spirit and mood of the time and what is accepted by the discipline. While acknowledging that this recent triangular theory requires testing in order to assess its validity and ongoing relevance, Sternberg (2018) proposes that what is new is the recognition that defying the crowd, oneself and the Zeitgeist can be seen as specific forms of creative action.

Stokes (2006) considers creativity in the context of literature, art, fashion, architecture, advertising and music. A key tenet of her argument is that constraints are needed for novel (creative) solutions to emerge, a view recently reiterated by Medeiros et al. (2018). Stokes (2006) contends that the creativity problem is both strategic and structural. It involves selecting (the strategy part) paired constraints (the structure part) that preclude reliable, successful responses and promote novel, surprising ones. Examples of composers whose task constraints inspired new creative solutions, included Claude Debussy (harmony), Igor Stravinsky (rhythm) and Arnold Schoenberg (melody). In terms of a detailed example in 
the visual arts, Stokes (2006) refers to Monet whose early constraints precluded dark-light contrasts, the illusion of depth and sharply outlined shapes. However these constraints "promoted" contrasting closely-valued colors, which, in turn, promoted flat patterns with soft-edged shapes that shared brushstrokes and colors" (Stokes, 2006). Recently, Sternberg (2018, p. 50) reinforces this view and refers to Claude Monet as an artist who "supremely met the definition of creative work: It was novel, surprising, and high in quality as well as impact".

\section{Stifling creativity}

While constraints may in fact be seen to promote creativity or creative solutions, numerous authors have highlighted the potential to stifle, or even effectively destroy creativity. Amabile (1998) contends that "there can be no doubt: creativity gets killed much more often than it gets supported". In a well-viewed and cited TEDx speech, Robinson makes a number of arguments about the curtailing of creativity in children (2006). He argues that education has the potential to harm creativity: "all kids have tremendous talents. And we squander them, pretty ruthlessly" (Robinson, 2006). Plucker et al. (2004, p. 84) agree and contend that creativity is often hampered in early education, arguing that classrooms "do not appear to be creativityfostering places, primarily due to the biases of teachers and traditional classroom organization". Sternberg $(2018$, p. 57) recently reinforced this theme, suggesting that "schools place so much emphasis on convergent problem solving that they may discourage creative thinking".

Plucker et al. (2004, p. 85) argue the problem extends beyond the classroom, given that creativity "is too often associated with negative assumptions and characteristics held by researchers, practitioners, and laypeople". The authors proceed to highlight a number of myths that hamper a positive view of creativity:

- People are born creative or uncreative;

- Creativity is intertwined with negative aspects of psychology and society;

- Creativity is a fuzzy, soft construct;

- Creativity is enhanced within a group.

In their study, Botella et al. (2013) identified that an artist's emotions can be as positive as they can be negative, with the latter a potential inhibitor of creativity. In Cropley et al. (2010) it is evidenced that for some artists, success can lead to a stifling or even drying up of creativity; Ralph Ellison and Harper Lee are cited as examples of key writers who, as far as is known, never produced another novel after the success of Invisible Man (Ellison, 1995) and To Kill a Mockingbird (Lee, 2014) respectively.

\section{Summary}

While the concept of creativity has been considered, studied and researched for centuries, it remains somewhat of an enigma. For a research field the study of creativity is very diverse and even disparate. In a recent interview, renowned psychologist Dean Keith Simonton commented that "my main hope for the psychology of creativity is that it acquire more theoretical coherence. Current research is all over the place" (Simonton \& Lebuda, 2019, p. 143). There is no consensus on what creativity means or entails, largely due to the inherent complexities of the concept. Given that the majority of literature focuses on theorizing these 
complex issues, there is limited research involving living artists. This study contributes to the discourse by engaging artists in a process of reflecting on the concept of creativity, allowing their voices to be heard.

\section{Exploring contemporary understandings of the creativity concept}

While interviews were considered for this research, an anonymous e-survey was chosen within the framework of a pragmatic and constructivist methodology (Creswell, 2014). The use of an online survey offers significant benefits in terms of cost-effectiveness and reach (Kemper et al., 2003). While it is acknowledged that there are disadvantages of using online surveys, including high drop-out rates, it has become a commonly used method of data gathering in contemporary research projects. An online survey designed using the SurveyMonkey platform allowed participants to reflect on their understanding of the concept of creativity, via multiple choice, multiple answer and short response questions. Individual pilot testing of the survey took place with three experienced creative artists, in order to ensure that the survey questions and response options were clear and understandable (Mertens, 2010). The three testers were each asked to verbally comment on their understanding of the questions as they proceeded through the survey, with the researcher taking notes recording their feedback and suggestions. At the end of the pilot testing process, a number of changes were made, including adjustments to the wording of questions to make their intention clearer to survey participants. In addition, response options for some questions were edited for further clarification, some were removed, while new options were also included in some cases.

The survey was subsequently made live and invitations to participate distributed to:

- A number of arts organizations based in Australia with a request they distribute the survey to their members;

- The researcher's network of academic and artist colleagues located in a range of countries;

- A considerable number of creative arts academics in several Western and English-speaking countries who had publicly available email address contacts (e.g. United Kingdom, United States (US), Scandinavia, South Africa, New Zealand) and

- The researcher's institutional alumni network.

The use of the snowball technique was encouraged, with participants invited to pass on the survey invitation to those they felt would potentially take part, be this their own networks, their colleagues or their students. The survey remained live for six months (March-August, 2019). At the conclusion of this period, 314 individuals had fully completed the survey.

This article focusses on four key areas relevant to creativity:

- Open-ended responses to the question of how participants define creativity;

- Views on the origins of each participant's creativity and what continues to inspire them;

- Reflections on what factors stifle individual and collective creativity and

- Any final (optional) thoughts that participants wished to present about the concept of creativity.

This article presents demographic information including participants' creative disciplines then explores these four key areas. 


\section{Profiling the survey participants}

Of the participants who fully completed the survey, 33\% identified as male, $65 \%$ as female, and $2 \%$ as other. In terms of ages, participants identified as follows:

- 18-24: 19\%;

- 25-34: $14 \%$;

- 35-44: 20\%;

- 45-54: 21\%;

- 55-64: $16 \%$

$-65+: 10 \%$.

In terms of participants' first language, the majority selected English (89\%). The remaining individuals selected languages from Europe (7\%), Asia (3\%), or Africa (1\%). In terms of geographical location, a majority of participants came from Australia (77\%), followed by England (6\%), US/Canada (4\%), South Africa (2\%) and New Zealand (2\%). The remainder were one or two participants from Asia (3\%), continental Europe (3\%), Scotland/Ireland (1\%), South America (1\%), or other (1\% - Ghana, Papua New Guinea). While the survey demographic was dominated by those located in Australia, there was some diversity of country and primary language. The following table summarizes participants' primary area of creative practice, years of experience in producing creative work and the average hours spent on creative practice per week (excluding administration, networking etc.).

Table 1 reveals that the participants represented a number of creative disciplines, that over half were very experienced (58\% with at least $20+$ years of practice), while nearly one third engage in an average of more than 20 hours of creative activity per week. The profile of the participants indicates they are able to provide a significant contribution to the survey questions and areas of inquiry.

Table 1. Survey participants' creative practice, experience and average weekly creative practice hours (source: created by author)

\begin{tabular}{|c|c|c|c|c|c|}
\hline Area of practice & $\mathrm{N}=314$ & $\begin{array}{l}\text { Years of } \\
\text { experience }\end{array}$ & $\mathrm{N}=314$ & $\begin{array}{c}\text { Average hours } \\
\text { creative practice per } \\
\text { week }\end{array}$ & $\mathrm{N}=314$ \\
\hline Visual or fine arts & $93(30 \%)$ & $0-4$ & $28(9 \%)$ & $1-9$ & $80(25 \%)$ \\
\hline Music and sound & $76(24 \%)$ & $5-9$ & $36(11 \%)$ & $10-19$ & $61(19 \%)$ \\
\hline $\begin{array}{l}\text { Multi-arts (several } \\
\text { art forms) }\end{array}$ & $42(13 \%)$ & $10-14$ & $39(13 \%)$ & $20-29$ & $55(18 \%)$ \\
\hline Design & $32(10 \%)$ & $15-19$ & $28(9 \%)$ & $30-39$ & $27(9 \%)$ \\
\hline Theatre or drama & $24(8 \%)$ & $20-29$ & $57(18 \%)$ & $40-49$ & $7(2 \%)$ \\
\hline Photography & $22(7 \%)$ & $30-39$ & $42(13 \%)$ & $50+$ & $8(3 \%)$ \\
\hline Film or video & $14(4 \%)$ & \multirow[t]{2}{*}{$40+$} & \multirow[t]{2}{*}{$84(27 \%)$} & \multirow{2}{*}{$\begin{array}{l}\text { Varies from week to } \\
\text { week or month to } \\
\text { month }\end{array}$} & \multirow[t]{2}{*}{$75(24 \%)$} \\
\hline Creative writing & $11(4 \%)$ & & & & \\
\hline
\end{tabular}




\section{Participants' understanding of the creativity term or concept}

Highly significant for the research focus was an open-ended question about participants' understanding of the term creativity. In order to identify key themes and synthesize the significant body of data, the complete list of responses was downloaded into an excel spreadsheet and coded inductively. Several comments included more than one theme, hence were allocated to two or more codes. The data was interrogated by the researcher on three separate occasions in order to ensure consistency and validity in the coding process. Table 2 below presents the synthesized data in terms of overarching themes (in descending order of frequency), the number and percentage of times each theme was referenced by participants, as well as an exemplar quote. Note that those themes that have less than a five percent response rate are included in the final "other" row.

Two dominant themes are clear in these responses: for this sample of artists creativity involves both the communication of ideas, concepts or feelings and the process of creation. Less prevalent are themes related to value or relevance, given that artists produce works which are not necessarily intended to serve a highly functional purpose but have a more aesthetic intent. Further interpretation of the themes in Table 2 also presents the opportunity to establish three meta-themes, namely: internal reward (e.g. expression, meaning making, passion, freedom), external connection (e.g. audience, storytelling, products), and actions (e.g. processes, innovation, exploration, problem solving).

\section{Participants' creativity: origins and inspirations}

The survey participants were asked two questions about inspiration. One asked them to reflect on from where they believe their creativity originates, the other who or what inspires their creativity. They could select as many of the provided response options as they wished

Table 2. Thematic analysis of participants' understandings of the creativity concept (source: created by author)

\begin{tabular}{|l|c|l|}
\hline \multicolumn{1}{|c|}{ Identified themes } & $\mathrm{N}=543$ & \multicolumn{1}{c|}{ Exemplar artists' reflections } \\
\hline Expression & $87(16 \%)$ & "Being able to express my feelings and thoughts" \\
\hline Process(es) & $84(15 \%)$ & "Perceptual and conceptual processes of artistic expression" \\
\hline Originality & $64(12 \%)$ & "Unique ideas communicated through creative processes" \\
\hline Imagination & $62(11 \%)$ & "Being able to use my imagination" \\
\hline Innovation & $40(7 \%)$ & "Being able to think of new and unique ideas/projects" \\
\hline Product(s) & $34(6 \%)$ & "To make things" \\
\hline Audience & $26(5 \%)$ & "Doing something in a way that captures peoples' attention" \\
\hline Divergent thinking & $29(5 \%)$ & "Looking outside the one, main, narrow path" \\
\hline $\begin{array}{l}\text { Other (N), (23\% of total } \\
\text { comments) }\end{array}$ & $\begin{array}{l}\text { Freedom (19), meaning making (18), problem solving (15), reward (10), } \\
\text { self (9), understanding (9), talent (8), exploration (7), inspiration (7), } \\
\text { mystical (7), passion (4), storytelling (4), misunderstood/overused (3), } \\
\text { collaborative (2), humanity (2), family (1) }\end{array}$ \\
\hline
\end{tabular}


and add additional comments. Tables 3 and 4 below summarize the data, with response selections presented in descending order of frequency and "other" comments analyzed in the bottom row of each table.

Table 3 and the additional comments reveal that participants acknowledge that while creativity is a key part of their cognitive processes (imagination, thinking, expression) and personality (part of me, DNA, passed on to me), it is a concept that also requires an extended period of work and practice in order to be realized. A small number of participants also indicated that they believed their creativity was influenced or inspired by "divine" elements and wider environments, including lived experiences and exposure to other life aspects and creativity beyond their own.

Table 3. Origins of participants' creativity (source: created by author)

\begin{tabular}{|l|c|}
\hline \multicolumn{1}{|c|}{ Creative origins (artists' reflections) } & $\begin{array}{c}\text { N (314) and \% } \\
\text { choosing option }\end{array}$ \\
\hline My imagination & $220(70 \%)$ \\
\hline Years and hours of study and experimentation & $186(60 \%)$ \\
\hline A part of my brain that enables me to be creative & $149(47 \%)$ \\
\hline It is part of me, part of my DNA & $133(42 \%)$ \\
\hline It was passed down to me by my parents and/or grandparents & $78(25 \%)$ \\
\hline It is a mystery to me; I really do not know & $53(17 \%)$ \\
\hline It is a gift from God or divine maker & $51(16 \%)$ \\
\hline $\begin{array}{l}\text { Additional comments: my environment(s) (8), a form of thinking or } \\
\text { expression (8), lived experiences (5), influential art, media, world (4), } \\
\text { consuming others' creativity (2) }\end{array}$ & $27(9 \%)$ \\
\hline
\end{tabular}

Table 4. Inspirations of participants' ongoing creativity (source: created by author)

\begin{tabular}{|l|c|}
\hline \multicolumn{1}{|c|}{ Creative inspirations (artists' reflections) } & $\begin{array}{c}\text { N (314) and \% } \\
\text { choosing option }\end{array}$ \\
\hline Other artists' work & $255(81 \%)$ \\
\hline A desire to express a positive or negative intuition or internal experience & $188(60 \%)$ \\
\hline The natural environment & $175(56 \%)$ \\
\hline My desire to make the world a better place & $143(45 \%)$ \\
\hline My teacher or teachers & $119(38 \%)$ \\
\hline The built environment & $101(32 \%)$ \\
\hline My family & $97(31 \%)$ \\
\hline My relationships with a partner or close friends & $88(28 \%)$ \\
\hline The pressure but excitement of making deadlines & $86(27 \%)$ \\
\hline My relationship with God or a divine essence & $41(13 \%)$ \\
\hline $\begin{array}{l}\text { Additional comments: my personality or approach (8), creating (7), things } \\
\text { that inspire me (7), meaning making (6), creative thinking (5), people (5), } \\
\text { collaborating (3), creative opportunities (3) }\end{array}$ & $44(14 \%)$ \\
\hline
\end{tabular}


While external influences dominate Table 4 in terms of what inspires participants' creativity (artists' work, natural, built environments, people), the need to engage in creative expression is also a major factor. This indicates that the act of engaging in creative practice itself becomes a form of inspiration, as does the desire to make a positive contribution to society (the world).

\section{Stifling creativity}

Survey participants were asked about what factors, if any, stifle their individual creativity; they could select as many answer options as they wished. The findings are summarized in Table 5 below in descending order in terms of frequency of response with additional comments summarized in the final row of the table.

Table 5 reveals that the three most significant inhibitors of creativity included two personal factors (self-criticism, negative emotions) and a very practical issue, namely the need to generate an income. The additional and optional comments supported these top three, with time, money and personal issues all cited and explained. Survey respondents were also asked to comment on what broader societal factors may stifle individual, group or cultural creativity. These findings are presented in Table 6 below.

Table 5. Factors stifling individuals' creativity (source: created by author)

\begin{tabular}{|l|c|}
\hline \multicolumn{1}{|c|}{ Factors stifling individual creativity (artists' reflections) } & $\begin{array}{c}\text { N (314) and \% } \\
\text { choosing option }\end{array}$ \\
\hline Me being too self-critical of my work & $170(54 \%)$ \\
\hline The need to make money in a non-arts job & $140(45 \%)$ \\
\hline My negative emotions from time to time & $138(44 \%)$ \\
\hline $\begin{array}{l}\text { Lack of personal skills required to communicate my finished creative } \\
\text { artefact(s) }\end{array}$ & $62(20 \%)$ \\
\hline Fitting into society's expectations and norms & $56(18 \%)$ \\
\hline Achieving some success which I find hard to repeat or aspire to again & $53(17 \%)$ \\
\hline Demanding clients & $50(16 \%)$ \\
\hline Medical conditions that I have & $49(16 \%)$ \\
\hline Current conventions and constraints regarding style, medium or aesthetics & $43(14 \%)$ \\
\hline Troublesome personal relationships & $30(10 \%)$ \\
\hline Nothing stifles my creative process & $28(9 \%)$ \\
\hline Curators intervene in my creative process or artistic intent & $24(8 \%)$ \\
\hline Critical feedback by other artists & $21(7 \%)$ \\
\hline Teachers that I have had & $21(7 \%)$ \\
\hline $\begin{array}{l}\text { Additional comments: time (12), competing priorities (9), budget or } \\
\text { financial constraints (8), profit over art for art's sake (4), finding professional } \\
\text { collaborators (3), achieving commercial viability (2), imposter syndrome (2), } \\
\text { seeking perfection (2), facility or external constraints (e.g. building codes, } \\
\text { studio space) (2), competition and exclusion (2) }\end{array}$ & $46(15 \%)$ \\
\hline
\end{tabular}


Table 6. Views on societal factors stifling creativity (source: created by author)

\begin{tabular}{|l|c|}
\hline \multicolumn{1}{|c|}{ Societal factors that stifle creativity (artists' reflections) } & $\begin{array}{c}\text { N (314) and \% } \\
\text { choosing option }\end{array}$ \\
\hline Schooling and/or education systems that do not prioritize or nurture creativity & $174(55 \%)$ \\
\hline $\begin{array}{l}\text { People who are overly critical or negative about the value of creativity in } \\
\text { contemporary society }\end{array}$ & $163(52 \%)$ \\
\hline $\begin{array}{l}\text { Perceptions in society that creativity is simply disruptive, "airy-fairy" or self- } \\
\text { indulgent }\end{array}$ & $151(48 \%)$ \\
\hline $\begin{array}{l}\text { A lack of acknowledgement in society of the need for creativity to solve wicked } \\
\text { or challenging problems }\end{array}$ & $147(47 \%)$ \\
\hline A lack of cultural understanding & $118(38 \%)$ \\
\hline All of these & $103(33 \%)$ \\
\hline $\begin{array}{l}\text { Parenting in the early years where creative acts are seen as bad behavior (e.g. } \\
\text { drawing on a wall, rearranging the food on a plate, ascribing to "make believe") }\end{array}$ & $78(25 \%)$ \\
\hline $\begin{array}{l}\text { Additional comments: poor budgets (7), political systems (3), poor quality art (3), } \\
\text { imposter syndrome (2), sexism and/or politics (2), mobile phone addiction (2) }\end{array}$ & $19(6 \%)$ \\
\hline
\end{tabular}

In Table 5 the survey participants rated the impact of teachers (education) as one of the lowest in terms of a stifling factor for their individual creativity. However when looking more broadly at society, in Table 6 these same artists rated education as the most significant negative factor. This would suggest that they have persevered through education systems but do not see them as being supportive of creativity in general. Poor perceptions regarding the value and worth of creativity in and for society were also rated highly by approximately half of all participants. The additional comments, while only very few, did offer valuable reflections, such as the impact of political systems, sexism and/or politics within the sector.

\section{Final reflections on creativity}

The final question provided an opportunity for survey respondents to add comments and thoughts about the concept of creativity. A total of eighty-seven individuals offered comments. One of the themes to emerge was the importance of creativity to humanity, society and the world, with the following examples of reflections received:

- Creativity needs to be valued more particularly in today's world which is in desperate need of creative and entrepreneurial people;

- Creativity is humankind's only survival hope;

- We lose our humanity without creativity;

- Our culture/civilization is due to our creativity - we dreamt it we made it we live it.

A number of reflections also referred to the benefits of creativity for health and wellbeing:

- Just that I love it, am grateful for it and that it is kept me alive more than once (in body, mind and spirit!);

- It is essential to people's mental health and wellbeing, everyone needs a creative outlet;

- Most people use creativity to bring joy, to educate and to make a difference. Good will always win. And it will always make us feel better, even in the bad times. 
There were also a number of reflections in relation to the need for creativity to be better supported, promoted and valued in both education and society:

- Creativity is grossly undervalued in education and therefore society;

- I believe it is sometimes (often?) neglected or underrated;

- Creativity is not a luxury and should be encouraged and supported at all levels (school, home and business);

- Needs to be valued at a very early age [prior to] school;

- Creativity [should be] encouraged and taught from mother's womb.

\section{Discussion}

While the findings of this study are limited to an e-survey only, the breadth of responses across a range of countries, age ranges and types of artist give the findings credibility, support some preliminary conclusions and contribute to the discourse on creativity. The data reveal that, for this group of artists, creativity is a multifaceted concept, with wide-ranging themes and influences. This reflects current literature and the area of systems theory, which indicates that creativity is a complex arrangement of interacting and interrelated factors (Kozbelt et al., 2010). Artists place significant importance on creativity as a means of expression and internal reward (e.g. freedom, meaning making). To some extent, this would suggest that the traditional definition of creativity as requiring value and appropriateness or applicability (Kaufman, 2009) needs to become more nuanced when describing the experiences of artists. The survey participants in this study generally focused on the pursuit of expression over novelty, thereby proposing that the perceived value of their work is more aesthetic than practical in nature. That is, works of art do not have the same immediate applicability that creativity and creative solutions might have in such fields as the sciences or business for example, or be expected to have by society. This tension was raised by many survey participants who argued that education and society need to more readily recognize the value of creativity through art-making.

In addition, the artists in this study highlighted the fact that process is critical to creativity, thereby continuing to reflect the idea of "creare" (to make), "kri" (to do) and "kere" (to grow). This clearly aligns with the participants' emphasis on expression, in that to reveal and communicate imagination, ideas or feelings there needs to be a system or process for doing so. While for many artists this is a very personal and internally focused process, some participants also felt that creativity should involve an element of uniqueness and/or innovation and that it considers audiences and society, thereby reflecting the more traditional definition of value and applicability. What is of additional interest from the findings is the recognition by a small number of participants that creativity can and does involve both the influence of and a relationship with a divine maker or god. Therefore, Greek philosophy and theory arguing that creativity relies on external forces (the "muse", daemons or "divine madness") continues to have some relevance today (Kaufman, 2009; Lubart, 2018; Schlesinger, 2009).

Given survey participants' emphasis on expression and process as key elements of creativity, it is to some extent logical that they identified imagination and years of study and experimentation as both key sources of their creativity. That is, there is a visionary or ethereal 
element (Friend, 2005) but the translation of this into outputs or artefacts requires a work ethic and system of practice, a process which is potentially highly individual in nature. In terms of ongoing sources of inspiration, peers' work was most frequently identified as the most significant. It is interesting that while artists in this study identified very internal or personal attributes as key to their creativity and process, they also acknowledged the wider art world and other creative artefacts as critical sources of inspiration. This extends to the natural and built environment, people (e.g. teachers, family, relationships) and a civic desire to contribute to the wider world. In a similar way to participants' definitions of creativity, with its emphasis on expression over utility, the findings here would suggest that on a continuum of personal expression through to significant public value, artists are located nearer to the personal expression end where they are either compelled or driven to create and realize their inner thoughts, imaginations and feelings.

This study also highlights the factors that impinge on creativity, both at the individual and personal level, and those perceived as being imposed or enacted by societies. For the participants in this study, it was clear that they see their highly self-critical nature and negative emotions from time to time as being a significant inhibitor, thereby reaffirming the literature (Kozbelt, 2016). They also reflected on the impact of time and money, with the need to financially sustain a creative practice a major concern for many, with paid work taking away their time and mental space for producing art. At a collective level, this group of artists believe that creativity is stifled both within schooling systems and education settings, as well as in broader populations where it may be seen by some as self-indulgent, ephemeral or nonessential. The impact of education is a key ongoing factor related to artists, for example, if creativity (and arguably art making) is embedded as a more critical component of education systems, this would potentially lead to a society that Plato argued - over two thousand years ago - would help create an "ideal state" with leaders of good character (Sloan Allen, 2002).

While creativity continues to be relevant to a wide range of areas in modern society, including the sciences, engineering, medicine, business and the humanities, it is artists themselves who have arguably attracted the most significant set of myths and perceptions in terms of who they are and what they do. This is due to the creative process containing a significant element of mystery and the typical outputs of an artist's creativity having a primarily aesthetic purpose, as compared to many other disciplines such as medicine or business for example, where creativity plays a far more functional and day to day role. With artists therefore, it is possible to propose that there is a higher level of personal investment, risk taking and selfexpectation, these factors also occurring across a long or very long period of time. That is, whereas creativity in business would usually be limited to the time a person practices in industry, for artists it is often the case that many enact creativity from an early age and continue this for the majority of their life, regardless of the extent of commercial return, employment in the arts and other measures of success. How to best understand and value this within education, political and socio-cultural systems remains worthy of ongoing research and inquiry, a situation acknowledged in recent literature (Lubart, 2018; Simonton \& Lebuda, 2019).

This article raises a number of key questions. What do the findings mean for key stakeholders in education and policy? Does creativity through art-making need to play a greater role in education systems and policy settings? Is the measured assessment and at times dis- 
trust of art (as espoused by Plato) still relevant today, or has this become an entrenched dogma which needs to be broken down over time? Who is best placed in education and policy settings to assess the value and impact of creativity through the arts? Given art is recognized as having a degree of power to transform thinking, to stir emotion and to raise awareness, could creativity through art-making be harnessed in better ways to make a stronger contribution to solving the current series of highly complex and serious challenges facing our world? These questions are not only worthy of serious consideration by key stakeholders, but offer researchers a number of directions for future inquiry and investigation, in order to further finesse our understanding of the potential for artistic creativity to make a difference in a rapidly changing world.

\section{Conclusions}

Creativity has provided us with the world's greatest artworks, with scientific, medical and technological discoveries, and it continues to profoundly transform societies. While at times it is used for negative purposes, such as the development of weapons of mass destruction or negative advertising and political campaigns, it is largely a positive force and one that arguably cannot and will never be completely replicated by machines, automation or artificial intelligence. In a global society which is facing a series of critical social, political and environmental challenges - and more so than ever before - it is perhaps the creative mind that offers our greatest weapon in combatting these same challenges. It is up to our leaders (in politics, education, planning, health and society) to continue to pay close attention not only to the value of creativity, but also to the further potential it may have for our day to day and longer-term challenges. Artists will remain a key part of this future, given their capacity to present a window on and mirror to the world and to human achievements and challenges, hence their value and contribution should never be underestimated but rather recognized and supported.

\section{References}

Amabile, T. (1998). How to kill creativity. Harward Business Review. https://hbr.org/1998/09/how-tokill-creativity

Bain, A. (2005). Constructing an artistic identity. Work, Employment and Society, 19(1), 25-46. https://doi.org/10.1177/0950017005051280

Blair, C. S., \& Mumford, M. D. (2007). Errors in idea evaluation: preference for the unoriginal? Journal of Creative Behavior, 41(3), 197-222. https://doi.org/10.1002/j.2162-6057.2007.tb01288.x

Boden, M. A. (2005). What is creativity? In S. Mithen (Ed.), Creativity in human evolution and prehistory (pp. 15-43). Series: Theoretical Archaeology Group. Routledge.

Botella, M., Glaveanu, V., Zenasni, F., Storme, M., Myszkowski, N., Wolff, M., \& Lubart, T. (2013). How artists create: creative process and multivariate factors. Learning and Individual Differences, 26, 161-170. https://doi.org/10.1016/j.lindif.2013.02.008

Bryant, W. D. A., \& Throsby, D. (2006). Creativity and the behavior of artists. In V. A. Ginsburgh \& D. Throsby (Eds.), Handbook of the economics of art and culture. Vol. 1. Series: Handbooks in 
Economics 25. K. J. Arrow \& M. D. Intriligator (Series Eds.) (pp. 507-529). Elsevier. https://doi.org/10.1016/S1574-0676(06)01016-7

Ceci, M. W., \& Kumar, V. K. (2016). A correlational study of creativity, happiness, motivation, and stress from creative pursuits. Journal of Happiness Studies, 17, 609-626.

https://doi.org/10.1007/s10902-015-9615-y

Chan, J., Bruce, J., \& Gonsalves, R. (2015). Seeking and finding: creative processes of 21 st century painters. Poetics, 48, 21-41. https://doi.org/10.1016/j.poetic.2014.11.001

Creswell, J. W. (2014). Research design: qualitative, quantitative, and mixed methods approaches. SAGE Publications, Inc.

Cropley, D. H., Cropley, A. J., Kaufman, J. C., \& Runco, M. A. (Eds.). (2010). The dark side of creativity. Cambridge University Press. https://doi.org/10.1017/CBO9780511761225

Csikszentmihalyi, M. (2014). The systems model of creativity: the collected works of Mihaly Csikszentmihalyi. Springer Science+Business Media.

Dorter, K. (1973). The Ion: Plato's characterization of art. The Journal of Aesthetics and Art Criticism, 32(1), 65-78. https://doi.org/10.2307/428704

Ellison, R. (1995). Invisible man. Vintage Books.

Freeland, C. (2002). But is it art? Oxford University Press.

Friend, N. (2005). Art: what matters? Arts and Humanities in Higher Education, 4(2), 159-172. https://doi.org/10.1177/1474022205051964

Ghadirian, A.-M., Gregoire, P., \& Kosmidis, H. (2001). Creativity and the evolution of psychopathologies. Creativity Research Journal, 13(2), 145-148. https://doi.org/10.1207/S15326934CRJ1302_2

Glăveanu, V. P. (2013). Rewriting the language of creativity: the five a's framework. Review of General Psychology, 17(1), 69-81. https://doi.org/10.1037/a0029528

Kaufman, J. C. (2009). Creativity 101. Series: The Psych 101 Series. Springer Publishing Company, LLC.

Kemper, E. A., Stringfield, S., \& Teddlie, C. (2003). Mixed methods sampling strategies in social science research. In A. Tashakkori \& Ch. Teddlie (Eds.), SAGE handbook of mixed methods in social and behavioral research (pp. 273-296). SAGE Publications, Inc.

Kozbelt, A. (2016). Process, self-evaluation, and lifespan creativity trajectories in eminent composers. In D. Collins (Ed.), The act of musical composition: studies in the creative process. Series: SEMPRE Studies in the Psychology of Music (pp. 27-52). Ashgate Publishing.

Kozbelt, A., Beghetto, R. A., \& Runco, M. A. (2010). Theories of creativity. In J. C. Kaufman \& R. J. Sternberg (Eds.). The Cambridge handbook of creativity (pp. 20-47). Cambridge University Press. https://doi.org/10.1017/CBO9780511763205.004

Lee, H. (2014). To kill a mockingbird. Harper.

Lubart, T. (Ed.). (2018). The creative process: perspectives from multiple domains. Series: Palgrave Studies in Creativity and Culture. V. P. Glăveanu \& B. Wagoner (Series Eds.). Palgrave Macmillan. https://doi.org/10.1057/978-1-137-50563-7

Lumsden, Ch. J. (1999). Evolving creative minds: stories and mechanisms. In R. J. Sternberg (Ed.), Handbook of creativity (pp. 153-168). Cambridge University Press. https://doi.org/10.1017/CBO9780511807916.010

Maley, A., \& Kiss, T. (2018). Creativity and English language teaching: from inspiration to implementation. Springer Nature. https://doi.org/10.1057/978-1-137-46729-4

Medeiros, K. E., Steele, L. M., Watts, L. L., \& Mumford, M. D. (2018). Timing is everything: examining the role of constraints throughout the creative process. Psychology of Aesthetics, Creativity, and the Arts, 12(4), 471-488. https://doi.org/10.1037/aca0000148 
Mertens, D. M. (2010). Research and evaluation in education and psychology: integrating diversity with quantitative, qualitative, and mixed methods. SAGE Publications, Inc.

Plucker, J. A., Beghetto, R. A., \& Dow, G. T. (2004). Why isn't creativity more important to educational psychologists? Potentials, pitfalls, and future directions in creativity research. Educational Psychologist, 39(2), 83-96. https://doi.org/10.1207/s15326985ep3902_1

Robinson, K. (2006). Do schools kill creativity? TED. https://www.ted.com/talks/sir_ken_robinson_do_ schools_kill_creativity?language=en

Runco, M. A. (2007). Creativity. Theories and themes: research, development, and practice. Elsevier Academic Press.

Sawyer, R. K. (2012). Explaining creativity: the science of human innovation. Oxford University Press, Inc.

Schlesinger, J. (2009). Creative mythconceptions: a closer look at the evidence for the "Mad Genius" hypothesis. Psychology of Aesthetics, Creativity, and the Arts, 3(2), 62-72. https://doi.org/10.1037/a0013975

Simonton, D. K., \& Lebuda, I. (2019). A golden age for creativity research: interview with Dean Keith Simonton. Creativity: Theories - Research - Applications, 6(1), 140-146. https://doi.org/10.1515/ctra-2019-0009

Sloan Allen, J. (2002). Plato: The Morality and Immorality of Art. Arts Education Policy Review, 104(2), 19-24. https://doi.org/10.1080/10632910209605999

Sternberg, R. J. (2018). A triangular theory of creativity. Psychology of Aesthetics, Creativity, and the Arts, 12(1), 50-67. https://doi.org/10.1037/aca0000095

Stokes, P. D. (2006). Creativity from constraints: the psychology of breakthrough. Springer Publishing Company, Inc.

Weisberg, R. W. (1994). Genius and madness?: A quasi-experimental test of the hypothesis that manicdepression increases creativity. Psychological Science, 5(6), 361-367. https://doi.org/10.1111/j.1467-9280.1994.tb00286.x

Wiggins, G. A., Tyack, P., Scharff, C., \& Rohrmeier, M. (2014). The evolutionary roots of creativity: mechanisms and motivations. Philosophical Transactions of the Royal Society B 370. https://www. ncbi.nlm.nih.gov/pmc/articles/PMC4321140/pdf/rstb20140099.pdf 